\title{
Microstructure and Wear Properties of the Quasi-Rapidly Solidified NiAl/ Cr(Mo,Dy) Hypoeutectic Alloy
}

\section{Y. Sheng}

Shenzhen Insititute, Peking University, Shenzhen, China

lysheng@yeah.net

The NiAl/Cr(Mo,Dy) hypoeutectic alloy was prepared by quasi-rapid solidification to investigate its microstructure and wear behavior. The results revealed that the quasi-rapid solidification refined the eutectic cell and NiAl/Cr(Mo) eutectic structure obviously. The alloy was composed of primary NiAl, fine $\mathrm{NiAl/Cr}(\mathrm{Mo})$ eutectic lamella and $\mathrm{Ni}_{5} \mathrm{Dy}$ phase. Compression test showed that the quasi-rapid solidification improved the mechanical properties of the alloy obviously. Wear test exhibited that alloy possessed excellent wear properties at about $1073 \mathrm{~K}$, which should be ascribed to the lubricant film formed by amorphous and $\mathrm{Cr}_{2} \mathrm{O}_{3}$ and $\mathrm{Al}_{2} \mathrm{O}_{3}$ nanoparticles. The alloy also exhibited relative good wear properties at $673 \mathrm{~K}$, which should be attributed to its high strength.

Keywords: $\mathrm{NiAl} / \mathrm{Cr}(\mathrm{Mo}, \mathrm{Dy})$, wear properties, rapid solidification, microstructure.

Introduction. Nickel aluminum $(\mathrm{NiAl})$ has been paid so much attention, because of its excellent properties at high temperatures, and it has been thought as a promising structure material to use in aero-engine [1-3]. While its insufficient high-temperature strength and room-temperature brittleness impedes its application. Recently, the investigations $[4,5]$ find that introducing of ductile phase in NiAl could improve its mechanical properties, which develops many kinds of NiAl based materials. Among them, $\mathrm{NiAl} / \mathrm{Cr}(\mathrm{Mo})$ eutectic alloy with lamellar eutectic structure becomes attractive, because of its good balance of room-temperature and high-temperature properties [6-8]. In spite of its enhancement on mechanical properties [9], its high-temperature creep property is still lower than that of the Ni-based superalloy $[10,11]$. The recent studies [12] exhibit that the introducing of rare earth (RE) element is helpful to its high-temperature properties, while the RE segregating along eutectic cell boundary leads to the decrease of its compressive ductility greatly. Based on previous research [13], rapid solidification could homogenize the distribution of RE and then increase the room-temperature compressive ductility. Moreover, previous research [14] has studied the tribological behavior of $\mathrm{NiAl}$ and exhibited its good tribological properties. However, few work has been done on wear behavior of $\mathrm{NiAl} / \mathrm{Cr}(\mathrm{Mo})$ eutectic alloy. Recently, it is reported that the oxide is helpful to the tribological properties by forming a glaze film [15]. While the researches $[16,17]$ show that the addition of rare earth in $\mathrm{NiAl} / \mathrm{Cr}(\mathrm{Mo})$ eutectic alloy can result in oxide. Furthermore, the increase of $\mathrm{NiAl}$ phase could promote the formation of alumina and then benefit to the wear properties. Therefore in the present paper, the $\mathrm{NiAl} / \mathrm{Cr}(\mathrm{Mo}, \mathrm{Dy})$ hypoeutectic alloy is fabricated by quasi-rapid solidification and its microstructure and wear behavior at elevated temperature are investigated.

1. Experimental Procedure. The alloy with composition of Ni-35Al-24Cr-5Mo0.1 Dy (at.\%) were melted under vacuum from pure metal chromium (99.9\%), nickel (99.9\%), dysprosium (99.8\%), aluminum (99.9\%) and molybdenum (99.8\%). To obtain the homogeneous samples, the alloy buttons were remelted and turned over for four times. The alloy was cut into pieces for quasi-rapid solidification. These pieces were put into a quartz tube and re-melted by induction coil; after then it was injected into a $\mathrm{Cu}$ mold $(\varnothing 10 \mathrm{~mm})$ to obtain the quasi-rapid solidified alloy. 
Specimens for microstructure characterization, wear and mechanical properties tests were cut from the quasi-rapid solidified alloy sample. The Phenom ${ }^{\mathrm{TM}}$ Pro scanning electron microscopy (SEM) was used to perform microstructure characterization. Constitute phase composition in the alloy was analyzed by the EPMA-1610 electronic probe microanalysis. JEOL-2100 transmission electron microscope (TEM) was employed to carried out the TEM characterization and the specimen for was cut from alloy with the thickness of $0.4 \mathrm{~mm}$. Then the specimen was polished to $30 \mu \mathrm{m}$ and shaped into $\varnothing 3 \mathrm{~mm}$ in size followed by twin-jet electropolishing. Compression sample $(4 \times 4 \times 6 \mathrm{~mm})$ was cut from the composite and mechanically grounded by 800 -grit $\mathrm{SiC}$ abrasive. Gleeble 3800 was employed to carried out the compression test at the strain rate of $1 \cdot 10^{-3} \mathrm{~s}^{-1}$. Dry sliding wear test was carried out on a HT-1000 type test machine, with the quasi-rapid solidified alloy pin rubbing against a SiC disk [14]. The wear testing carries out at a linear speed of $0.2 \mathrm{~m} / \mathrm{s}$ for $100 \mathrm{~min}$ under the load of $30 \mathrm{~N}$ in air at different temperatures. Wear rate is presented in terms of a friction coefficient by normalizing the volume loss with load and sliding distance. SEM and TEM were applied to observe the worn surface and the cross section of the specimen.

\section{Results and Discussion.}

2.1. Microstructure and Compressive Properties. Microstructure of $\mathrm{NiAl} / \mathrm{Cr}(\mathrm{Mo}, \mathrm{Dy})$ hypoeutectic alloy prepared by quasi-rapid solidification is exhibited in Fig. 1. Clearly, grey $\alpha$-Cr phase and black NiAl matrix are the main components that comprise the eutectic cell and coarse intercellular zone, as shown in Fig. 1a and b. In the eutectic cell, $\alpha$-Cr and $\mathrm{NiAl}$ lamellas extend from the center to the boundary. The thickness of the eutectic lamella near the boundary is bigger than that in the center. Along the eutectic cell boundary, a small white phase can be observed and the energy disperse spectroscopy (EDS) analysis exhibits it mainly contains Dy and Ni. TEM and selected area diffraction pattern (SADP) examinations on the phase along eutectic cell boundary confirm it to be $\mathrm{Ni}_{5} \mathrm{Dy}$ with hexagonal crystal structure $(a=0.4856 \mathrm{~nm}, c=0.3969 \mathrm{~nm})$ and $\mathrm{P} 6 / \mathrm{mmm}$ space group, as shown in Fig. 1c. TEM observation also revealed that the small precipitates distributed in $\alpha$-Cr and $\mathrm{NiAl}$ phase, which should be $\beta$-NiAl and $\alpha-\mathrm{Cr}$ particles precipitate, respectively. Moreover, further observation on the eutectic cell exhibits that interface dislocations with hundreds nanometer in width are found on the phase boundary, as shown in Fig. 1d.
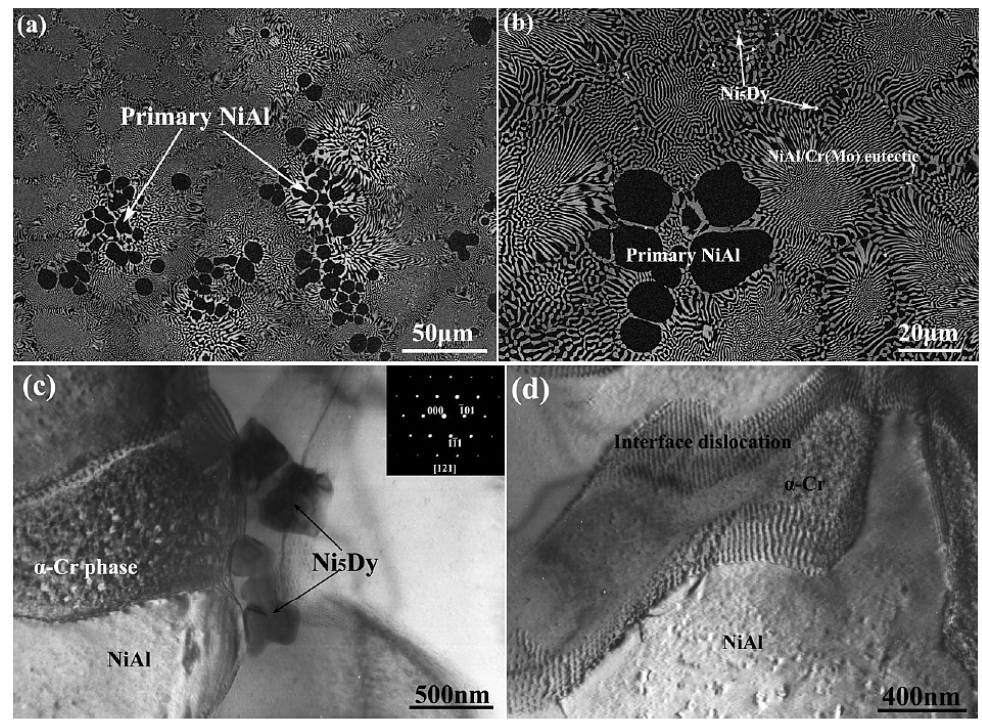

Fig. 1. SEM image of quasi-rapidly solidified NiAl/Cr(Mo,Dy) hypoeutectic alloy (a); morphology of $\mathrm{Ni}_{5} \mathrm{Dy}$ phase along eutectic cell boundary (b); TEM morphology of $\mathrm{Ni}_{5} \mathrm{Dy}$ and precipitates in $\alpha-\mathrm{Cr}$ phase (inset picture showing SADP of $\mathrm{Ni}_{5} \mathrm{Dy}$ phase) (c); TEM image of interface dislocation along $\mathrm{NiAl} / \alpha-\mathrm{Cr}$ phase boundary (d). 
The compressive yield strength variation of binary NiAl alloy and $\mathrm{NiAl} / \mathrm{Cr}(\mathrm{Mo}, \mathrm{Dy})$ hypoeutectic alloy prepared by quasi-rapid solidification at elevated temperatures is shown in Fig. 2. Clearly, with the temperature increasing, the yield strength of alloys both decreases gradually. However, compared with the binary NiAl alloy, the descent rate of quasi-rapidly solidified $\mathrm{NiAl} / \mathrm{Cr}(\mathrm{Mo}$,Dy) hypoeutectic alloy is higher, especially between 600 and $900 \mathrm{~K}$. Whatever, the rapid solidification and strengthening phase have increased the yield strength of $\mathrm{NiAl} / \mathrm{Cr}(\mathrm{Mo}, \mathrm{Dy})$ hypoeutectic alloy greatly. Its yield strength at $1273 \mathrm{~K}$ is almost the same with that of binary NiAl alloy at $673 \mathrm{~K}$. The improved yield strength of $\mathrm{NiAl} / \mathrm{Cr}(\mathrm{Mo}, \mathrm{Dy})$ hypoeutectic alloy should be attributed to the $\alpha$-Cr phase and the refined eutectic structure resulted by the quasi-rapid solidification.

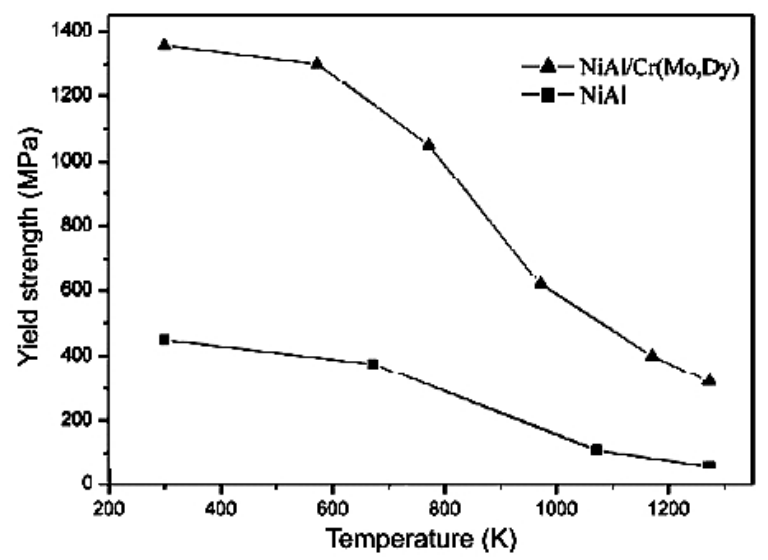

Fig. 2. Compressive yield strength of $\mathrm{NiAl}$ and quasi-rapidly solidified $\mathrm{NiAl} / \mathrm{Cr}(\mathrm{Mo}, \mathrm{Dy})$ hypoeutectic alloy at different temperatures.

2.2. Wear Properties. The average friction coefficient and wear rate of $\mathrm{NiAl} /$ $\mathrm{Cr}(\mathrm{Mo}, \mathrm{Dy})$ hypoeutectic alloy prepared by quasi-rapid solidification changes obviously with the temperatures, as shown in Fig. 3. With the temperature increasing, the friction coefficient has two valley values at 673 and $1073 \mathrm{~K}$, respectively. The friction coefficient reaches its minimum value at $1073 \mathrm{~K}$. The evolution of the wear rate is different from the friction coefficient. It keeps the uptrend with temperature increasing but drop sharply at $1073 \mathrm{~K}$. The wear rate gets the minimum value at $1073 \mathrm{~K}$.

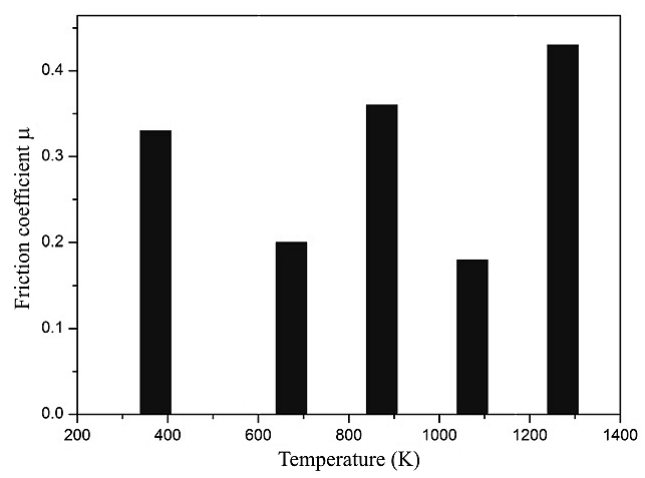

a

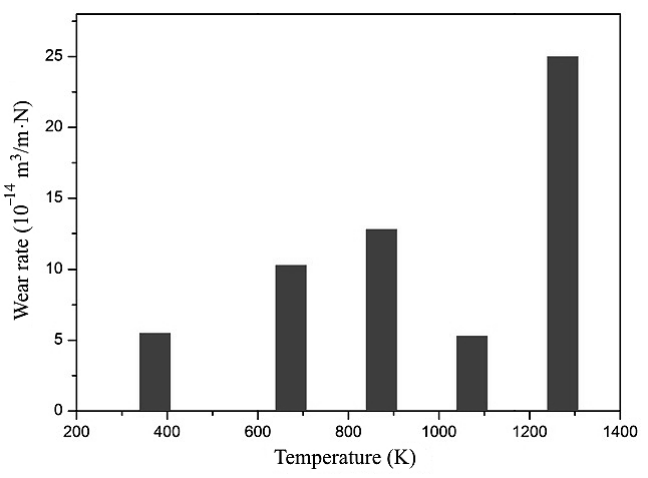

$\mathrm{b}$

Fig. 3. Friction coefficient (a) and wear rate (b) of quasi-rapidly solidified $\mathrm{NiAl} / \mathrm{Cr}(\mathrm{Mo}, \mathrm{Dy})$ hypoeutectic alloy at elevated temperatures. 
2.3. Worn Surface. To explain the changing of the wear properties, observation on the worn surface of $\mathrm{NiAl} / \mathrm{Cr}(\mathrm{Mo}, \mathrm{Dy})$ hypoeutectic alloy fabricated by quasi-rapid solidification is carried out. Figure 4 shows the typical morphology of the worn specimen at elevated temperatures. At relative low temperature, scratch resulted by abrasion is the main characteristics, as shown in Fig. 4a. Due to the brittleness of the alloy at low temperatures, debris and cracks can be found on the worn surface. When the temperature increases to $673 \mathrm{~K}$, worn surfaces demonstrate the rheology feature, as shown in Fig. 4b. When the temperature increases to $873 \mathrm{~K}$, furrow becomes the main characteristic, as shown in Fig. 4c. The deep furrows on the worn surface could explain the peak value of wear rate and friction coefficient at this temperature. With the temperature comes to $1073 \mathrm{~K}$, the worn surface is smooth and has no furrow, as shown in Fig. 4d. When the temperature increases further, the worn surface is spalled partly by the friction pair and exhibits ripple morphology, as shown in Fig. 4e. SEM observation on the worn specimen at $1073 \mathrm{~K}$ reveals that a relative thick lubricant film with several micrometers in size is generated on the surface of the matrix, as shown in Fig. 4f. The observation also exhibits that the matrix near the worn surface has experienced a high deformation. The inset SADP reveals that the lubricant film is mainly composed of $\mathrm{Cr}_{2} \mathrm{O}_{3}$ amorphous phase and $\mathrm{Al}_{2} \mathrm{O}_{3}$ nanocrystalline particle.

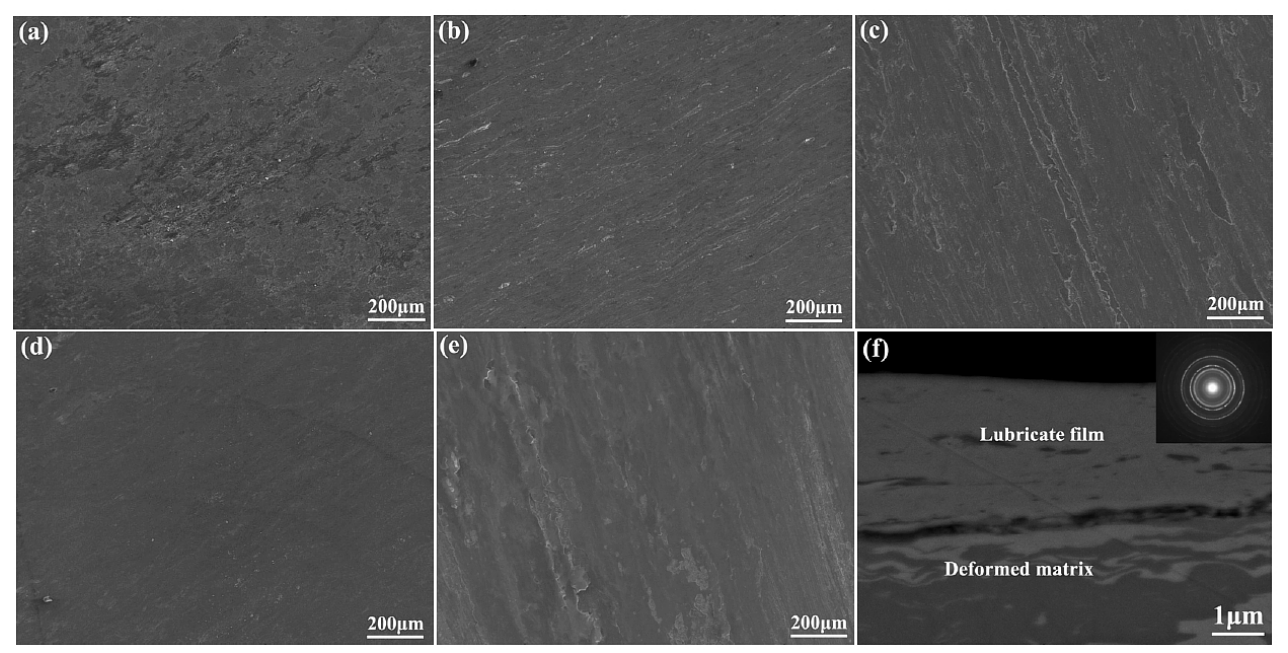

Fig. 4. Morphology of worn surface of quasi-rapidly solidified NiAl/Cr(Mo,Dy) hypoeutectic alloy at different temperatures: 373 (a), 673 (b), 873 (c), 1073 (d), and $1273 \mathrm{~K}$ (e); cross-sectional image of the worn specimen at $1073 \mathrm{~K}$ (inset picture showing the SADP) (f).

According to the recent researches [18, 19], the wear properties of the material is related with its strength and tribological product. High strength could increase the wear resistance, and the debris could introduce the self-lubricating medium. In the present paper, the quasi-rapid solidification increases the strength of $\mathrm{NiAl} / \mathrm{Cr}(\mathrm{Mo}, \mathrm{Dy})$ hypoeutectic alloy obviously. The formation of oxides of $\mathrm{Ni}, \mathrm{Al}$ and $\mathrm{Cr}$ introduce the self-lubricating medium, which is helpful to decrease the wear rate and friction coefficient. But at the lower temperature, the brittle $\mathrm{NiAl}$ phase can't withstand the long-term grind, which results in the formation of microcrack. Though the increased temperature could enhance the selflubricating medium, the stiffness of the matrix can't reserve them. Therefore, the friction coefficient decrease but wear rate increase below $673 \mathrm{~K}$. When the testing temperature increases further, it will exceed the ductile to the brittle transition temperature, so the NiAl matrix becomes softer. Then one can see that the friction coefficient and wear rate both exhibit obvious ascend tendency in the range of 673 to $873 \mathrm{~K}$. At $1073 \mathrm{~K}$, the selflubricating medium has formed the lubricant film on the worn surface, which decreases the 
wear rate and friction coefficient greatly. If testing temperature becomes higher, the matrix can't support the lubricant film for long time and result in the spalling of the worn surface. It can be deduced that at low temperature, microfracture is the main characteristic and strength play a dominant role. At high temperature, oxidation and self-lubricating is the main mechanism.

\section{Conclusions}

1. A NiAl/Cr(Mo,Dy) hypoeutectic alloy, which consists of fine $\mathrm{NiAl} / \mathrm{Cr}(\mathrm{Mo})$ eutectic lamella, primary $\mathrm{NiAl}, \mathrm{Ni}_{5} \mathrm{Dy}$ phase, is fabricated by quasi-rapid solidification. The compressive properties of $\mathrm{NiAl} / \mathrm{Cr}(\mathrm{Mo}, \mathrm{Dy})$ hypoeutectic alloy is improved by the quasirapid solidification.

2. The $\mathrm{NiAl} / \mathrm{Cr}(\mathrm{Mo}, \mathrm{Dy})$ hypoeutectic alloy prepared by quasi-rapid solidification exhibits relative good wear properties below $673 \mathrm{~K}$ and excellent wear properties at temperature at about $1073 \mathrm{~K}$.

3. The excellent wear properties at high temperature could be ascribed to the protecting lubricant film which is composed of amorphous and $\mathrm{Cr}_{2} \mathrm{O}_{3}$ and $\mathrm{Al}_{2} \mathrm{O}_{3}$ nanoparticles. The relative good wear properties at low temperature could be attributed to the high strength of the alloy.

Acknowledgments. The authors are grateful to the Strategic New Industry Development Special Foundation of Shenzhen (JCYJ20140419114548515), the Shenzhen International Cooperative Research Project (GJHZ20140419114548516) and the Shenzhen Technology Innovation Plan (CXZZ20140419114548507) for financial support.

1. D. B. Miracle, "Overview No. 104 the physical and mechanical properties of NiAl," Acta Metal. Mater., 41, No. 3, 649-684 (1993).

2. L. Y. Sheng, W. Zhang, J. T. Guo, et al., "Effect of Au addition on the microstructure and mechanical properties of NiAl intermetallic compound," Intermetallics, 18, No. 4, 740-744 (2010).

3. H. Q. Ye, "Recent developments in high temperature intermetallics research in China," Intermetallics, 8, No. 5-6, 503-509 (2000).

4. L. Y. Sheng, Y. Xie, T. F. Xi, et al., "Microstructure characteristics and compressive properties of NiAl-based multiphase alloy during heat treatments," Mater. Sci. Eng. A, 528, No. 29-30, 8324-8331 (2011).

5. L. Y. Sheng, W. Zhang, J. T. Guo, et al., "Microstructure evolution and mechanical properties' improvement of NiAl-Cr(Mo)-Hf eutectic alloy during suction casting and subsequent HIP treatment," Intermetallics, 17, No. 12, 1115-1119 (2009).

6. H. Bei and E. P. George, "Microstructures and mechanical properties of a directionally solidified NiAl-Mo eutectic alloy," Acta Mater., 53, No. 1, 69-77 (2005).

7. L. Y. Sheng, J. T. Guo, T. F. Xi, et al., " $\mathrm{ZrO}_{2}$ strengthened $\mathrm{NiAl} / \mathrm{Cr}(\mathrm{Mo}, \mathrm{Hf})$ composite fabricated by powder metallurgy," Prog. Nat. Sci.-Mater. Int., 22, No. 3, 231-236 (2012).

8. D. R. Johnson, X. F. Chen, B. F. Oliver, et al., "Processing and mechanical properties of in-situ composites from the NiAl-Cr and the NiAl-(Cr,Mo) eutectic systems," Intermetallics, 3, No. 2, 99-113 (1995).

9. L. Y. Sheng, L. Nan, W. Zhang, et al., "Microstructure and mechanical properties determined in compressive tests of quasi-rapidly solidified NiAl-Cr(Mo)-Hf eutectic alloy after hot isostatic pressure and high temperature treatments," J. Mater. Eng. Perform., 19, No. 5, 732-736 (2010). 
10. L. Y. Sheng, F. Yang, J. T. Guo and T. F. Xi, "Anomalous yield and intermediate temperature brittleness behaviors of directionally solidified nickel-based superalloy," Trans. Nonferr. Met. Soc. China, 24, No. 3, 673-681 (2014).

11. L. Y. Sheng, F. Yang, T. F. Xi, et al., "Microstructure and elevated temperature tensile behaviour of directionally solidified nickel based superalloy," Mater. Res. Innov., 17, No. S1, 101-106 (2013).

12. L. Y. Sheng, F. Yang, T. F. Xi, et al., "Microstructure and room temperature mechanical properties of NiAl-Cr(Mo)-(Hf,Dy) hypoeutectic alloy prepared by injection casting," Trans. Nonferr. Met. Soc. China, 23, No. 4, 983-990 (2013).

13. L. Y. Sheng, F. Yang, T. F. Xi, et al., "Improvement of compressive strength and ductility in NiAl-Cr(Nb)/Dy alloy by rapid solidification and HIP treatment," Intermetallics, 27, 14-20 (2012).

14. J. A. Hawk and D. E. Alman, "Abrasive wear behavior of NiAl and NiAl-TiB 2 composites," Wear, 225-229, Part 1, 544-556 (1999).

15. O. Ozdemir, S. Zeytin, and C. Bindal, "Tribological properties of NiAl produced by pressure-assisted combustion synthesis," Wear, 265, No. 7-8, 979-985 (2008).

16. L. Y. Sheng, L. J. Wang, T. F. Xi, et al., "Microstructure, precipitates and compressive properties of various holmium doped NiAl/Cr(Mo,Hf) eutectic alloys," Mater. Des., 32, No. 10, 4810-4817 (2011).

17. L. Y. Sheng, J. T. Guo, Y. X. Tian, et al., "Microstructure and mechanical properties of rapidly solidified NiAl-Cr(Mo) eutectic alloy doped with trace Dy," J. Alloy Compd., 475, No. 1-2, 730-734 (2009).

18. L. Y. Sheng, C. Lai, F. Yang, et al., "Microstructure and wear behaviour of ceramic particles strengthening NiAl based composite," Mater. Res. Innov., 18, No. S4, 544-549 (2014).

19. T. Aizawa, A. Mitsuo, S. Yamamoto, et al., "Self-lubrication mechanism via the in situ formed lubricious oxide tribofilm," Wear, 259, No. 1-6, 708-718 (2005). 